\title{
The Role of Moving Images in the Teaching of Biology in Adult Education
}

\author{
Simone Paixão Araújo Pereira ${ }^{1}$, Maria Helena da Silva Carneiro ${ }^{2}$ \\ ${ }^{1}$ Federal Institute of Goias, Luziânia, Brazil \\ ${ }^{2}$ University of Brasília, Brasília, Brazil \\ Email: simonepaixao@ifg.edu.br
}

Received October $28^{\text {th }}$, 2013; revised November $28^{\text {th }}$, 2013; accepted December $5^{\text {th }}, 2013$

\begin{abstract}
Copyright ( 2014 Simone Paixão Araújo Pereira, Maria Helena da Silva Carneiro. This is an open access article distributed under the Creative Commons Attribution License, which permits unrestricted use, distribution, and reproduction in any medium, provided the original work is properly cited. In accordance of the Creative Commons Attribution License all Copyrights (C) 2014 are reserved for SCIRP and the owner of the intellectual property Simone Paixão Araújo Pereira, Maria Helena da Silva Carneiro. All Copyright @ 2014 are guarded by law and by SCIRP as a guardian.
\end{abstract}

Taking into consideration the pedagogical potential of images, we proposed to analyze the contribution documentaries produced for educational purposes, the understanding of concepts related to entomology. Therefore, we organized a sequence of biology teaching. In our work, we developed diversified activities that were planned and organized in advance, but to create teaching situations where students could analyze their previous knowledge. The teaching sequence was subdivided into three meetings, which were used insect images, text problem situation and documentaries produced for educational purposes. All activities were audio recorded. Participated in the activities of high school students involved in a program of Adult Education. After analyzing the data generated, it can be concluded that these documentaries supported the development of more complex representations, which leads us to infer that this type of teaching resource is an important additional resource of learning, since it is widely considered by students.

Keywords: Science Education; Adult Education; Entomology

\section{Introduction}

The organization of the teaching of science has had numberless proposals of transformation in recent years. In general, the changes presented aim at bettering the conditions to form the scientific spirit of students in light of the historic-cultural conditions of society. The alterations attempt to situate science and its teaching in space and time, constantly emphasizing certain aspects considered more relevant for a person's scientific understanding and action in the world through knowledge which is generally different from what is commonly held.

The school, at the same time, is strongly committed to quailty education which can favor the exercise of citizenship with responsibility. The academic subjects taught to the students are considered as a part of a necessary baggage to facilitate the comprehension of new forms of interpreting everyone's surrounding reality and to acquire the necessary conditions for discussing, debating, expressing opinions and even intervening in social matters which characterize the present moment in history. Some situations in the teaching of science have been limited to the memorization of words, systems of classification and formulas by means of didactic strategies in which the students learn the scientific terms, but do not construct meanings.

We live in a time when knowledge increases in exponential proportions, making it practically impossible for a person to assimilate all the information at hand. We need basic knowledge to aid our interpretation and comprehension of the new information we receive and will arise throughout our life. The construction of elementary scientific knowledge capacitates us to achieve the understanding of ever more complicated concepts. The teaching of Biology should therefore equip the student to act in different daily situations and expand his understanding of reality.

\section{Why Teach Entomology?}

Studies carried out in contexts different from our own showed that adults construct representations of the insects that are more at hand with affective characteristics, hardly having recourse to scientific criteria to identify them. Costa Neto and Carvalho (2000), surveying university students reported that the construction of the ethnological category "insect" is carried out through ambiguous perceptions, with the consulted students showing both reactions of fear, disgust and scorn with regard to the organisms included in the ethno zoological domain "insect" and attributions of ecological, esthetic and utilitarian functions. Later, Lima et al. (2010) presented the results of a study of the perception of a community in the interior of Pernambuco with regard to insects. In this study the insects that were most cited by the inhabitants were roaches, flies and ants, with $57.8 \%$ of women manifesting sentiments of repulsion and fear of insects, corroborating the cultural perception of insects in our daily life. Those studies strengthen our choice in adopting this theme as the object of our research since the scientific concept, despite being approached starting in the initial grades continues to be strongly characterized by affective aspects of fear among the 
adult population.

The negative vision with regard to insects could have greater consequences influencing feelings and attitudes with regard to these organisms, leading individuals to aggressive attitudes such as wanting immediately to exterminate the insect upon encountering it. Knowledge of the biology and ecology of insects can help to understand the role of this group in the environment as well as to change human relations with it. So, it is vital that in formal teaching there be an increase of sensibility in relation to the importance of conserving insects and that to that end there be provision for pedagogical situations that enable reflection on the part of the students so that they may be encouraged to reexamine their representations.

Besides that, the study of living beings of the group of animals is planned for the second year of Intermediate Education in the Program of Professional Integration in the modality of young people and adults-PROEJA.

From this perspective, the present study sought to understand the teaching and learning process of entomology and the role of documentaries in this process.

\section{The Andragogical View-Regarding the Adult's Process of Learning}

Teachers should organize conditions to favor the learning of the students, starting with the establishment of partnerships with the community in order to adjust their professional obligetions to the values of social justice, equality of opportunities and the edification of citizenship. Andragogy, the science which studies the processes of teaching-learning in the education of adults, according to Ludojoski (1972), is differentiated from Pedagogy, especially by different presuppositions with regard to the concept of student, the role of his experience of learning, disposition to learn, orientation for learning and motivation for learning. This author affirms that that the adult is a person considered as a being in historical development who, in view of what he inherited from his infancy, his passage through adolescence and on his way to old age, continues his process of the individualization of his being and of his personality. For Ludojoski (1972), in the strict sense, the education of adults is understood as complementing the insufficiencies that adults are still carrying from their primary formation or in the substitution of primary education in the case of its absence. The term "andragogy” has been used by some as a code word to identify education and learning on the part of adults. It has been used by others to designate different strategies and methods employed to help adults to learn. Andragogy became popular in the 70's and 80's in the United States of America, through the work of Malcolm Knowles and other collaborators. But its original introduction in the United States was in 1926, by Eduard Lindeman. Meanwhile, Alexander Kapp (1833), nearly a century before, was the author of the term and initial concept. Malcolm Knowles was in his own time an important reference in terms of the formation of adults, especially through his contribution to the construction of the "andragogical model" of adult learning. For Henschke and Cooper (2006), the development of Knowles' concept was based on his various presuppositions regarding the nature of the adult student. Savicevic (1999 as cited in Rachal, 2002: p. 210) defined andragogy as a scientific discipline which deals with the problems of education and learning on the part of adults in all their manifestations and expressions, formal or informal, organized or self-directed, and including most of the person's life. For that author, it is tied up to culture, related to performance in professional activities and tasks, family, social and community responsibilities functions and the use of leisure time. All these areas make up the domain of the work of adult education. The particularities of this modality of teaching challenge educators to seek to understand better the factors related to a return to the school environment and the motivation to learn. With regard to this latter aspect Knowles (1984) reminds us: Though it is recognized that adults respond to some external motivations, a better job, a raise in salary, as predicates of the andragogical model, the most powerful motivators are internal ones such as self-esteem, recognition, better quality of life, better self-confidence, self realization and the like (Knowles, 1984 quoted by Rachal, 2002: p. 220).

We understand that the author emphasizes the more influential individual and internal variables on the process of teaching, thus privileging as motivational factors for the learning subjective and psychological aspects over professional and external matters. With this understanding the researcher should examine or create situations of learning in which the student can perform a significant or even the principal role in the determination of the learning processes.

The "facilitation" of learning by adults in their specificity would then be for Knowles the foundation for his proposal of Andragogy. According to Inês (2009), for Knowles the ideal facilitator is the one who: sees the student as someone capable of self-direction, capable of manage his own process of growth; [Knowles] conceives adult learning as a process of self-development. Inês (2009) affirms that the teacher who acts from an andragogical perspective, conceives learning as more significant if it arises from intrinsic motivation and that such a teacher emphasizes the creation of a facilitating climate of learning characterized by cordiality, mutual trust and respect, interest and attention and informality, that is, non-directivity; he involves the student in the definition of the objectives always so that they are significant for him, for example, through the socalled "learning contracts"; [the teacher] develops sequential experiences of learning which consider the similarities of the group (common interests, for example) and the individual differences as organizational principles for the learning projects; he chooses techniques and materials that actively involve the student in his process of self-questioning.

Adults tend to have a perspective of immediacy of application for most of their learning. They dedicate themselves to learn mostly in response to the pressures they feel from their present life situation. For adults, education is a process of bettering their capacity to deal with the problems of life which they are encountering there and then. Besides that, the adult student has an experience based on his daily life. For that reason they develop many patterns and forms of perceiving and understanding that experience and they have a series of well organized facts, meanings, values and strategies which at the same time define, create and restrict their representative model of reality. Lived experience is an essential component of the adult's learning and constitutes a foundation for new learning or its inevitable obstacle. Teaching based on student experiences can promote learning more effectively because it takes into account the interests of the students and seeks to relate the student's representation of reality to the interpretation of science regarding the same events. Some authors frequently underline the importance of analogies and metaphors to lend initial meaning and intelli- 
gibility to new concepts (Ortony, 1975; Belth, 1977; Black, 1962 quoted by Posner et al., 1982).

In that sense the critical role of the teacher, therefore, is that of creating a rich work space in which the students can learn and later orient their interaction with the environment so as to perfect their way of learning from it.

"In fact the principal impulse of modern adult educational technology is toward inventing techniques to involve adults in ever deeper processes of self-diagnosis regarding their own necessities of ongoing learning, in the formulation of their own objectives of learning, in the sharing of responsibility for the conception and realization of their learning activities and in the evaluation of the respective advances in the direction of their objectives.” (Knowles, 1970 quoted by Vogt, 2007: p. 43).

For Knowles, to stress the sense and functionality of new knowledge should constitute an identifying trait of an andragogical perspective. In this approach it is understood that adults feel more motivated to learn when they understand the advantages and benefits of a particular piece of knowledge.

In the andragogical perspective, teachers are considered as the mediators of the process of adult learning, recognizing the importance of their experience as a foundation of planning and elaboration of the teaching project so that in this activity the student may be able to evaluate himself and ponder his profile before and during the teaching process and how it approaches his aspirations.

With respect to the adult's possession or not of a consolidated and elaborated self identity stemming from his experience, it happens that in situations in which his experience is not valued, he may feel rejected as a person. Such considerations promote a reflection on the relevance of valuing the experience of the student in the process of teaching-learning.

"It is in this sense that to teach is not merely to transfer knowledge, contents, nor to form; it is the action through which a creator subject gives form, style or soul to an undecided and accommodated body. There is no teaching without learning; the two explain one another; their subjects, despite their differences are not reduced to the condition of objects one of the other. He who teaches learns while teaching and he who learns teaches while learning” (Freire, 2002: p. 12).

Freire demonstrated how educators of adults can, starting from the daily problems and perspectives of the student, develop a series of educational materials in areas that are of interest to the students. Through dialogue we can involve the students who are facing a dilemma, provoke and challenge the cultural presuppositions through ways of thinking, perceiving, feeling and behaving. Emphasis is given to equality and reciprocity in the construction of a support group in which students can share lived experiences and construct new perspectives. Conceptual learning can be integrated with emotional and aesthetic experience. This implies educational experiences that challenge the suppositions taken for certainties.

\section{Methodology}

In order to reach our objectives we plan a sequence of teaching to be developed in the classroom based on the propositions of Zabala (1998) in his book A Prática Educativa. Those activities were developed in a public institution of Professional Education which aims to form and qualify professionals for the diverse sectors of economy in basic and higher levels. Originally, 23 students participated in the study of the Program of
Professional Integration in the modality of Education of Young People and Adults-PROEJA.

The teaching sequence consisted of three collective meetings of an hour and a half and an individual meeting in which we interviewed the participants. Considering the extent of the work we will present it in more detail only in context of the second meeting. The first meeting was dedicated to the study of the representations of the students. In the second meeting, we aimed at showing some relationships established between insects and man. Dialogue oriented the activity which aimed at helping the students to compare their successive failures in search of coherence, to perceive the differences between their representations and the representations of their colleagues and confront them with the scientific knowledge presented. In order to achieve this objective we employed educational documentaries and a text which contained a problem situation. We stressed that the choice of the video which is part of the collection was determined in view of the results presented by the students in the previous meeting. That second stage of the teaching sequence was divided into two moments.

\section{First Stage: Insects and the Environment}

The activity consisted in presenting documentaries that showed the relationships between insects and the environment. The DVD used was "Os insetos e o homem” ["Insects and Man”], produced by GIC/IMAGO of the Federal University of Rio de Janeiro-UFRJ, which was conceived so that the image be used as an instrument for the diffusion/teaching of Science. In that respect we point out that in this activity the documentaries chosen dealt with insects that were mentioned in the narratives of the experiences produced in the second stage of the first meeting. The insects that were most mentioned were the mosquito and the butterfly, [so] we presented the documentaries: "Estudando o mosquito" ["Studying the Mosquito"] and "Voo unido" ["United Flight"] which refer to the reproductive and behavioral characteristics of mosquitoes and butterflies respectively, besides exploring cultural aspects. The documentaries were presented and the students were divided into groups. Each group attended the documentaries and dialogued about the information presented and recorded their opinions. Since their duration averaged 5 minutes, they were shown the first time without interruption, followed by a second showing with pauses for a better discussion of the information.

Besides the presentation and discussion of the videos, a problem situation was presented so that they could discuss it within each group and later present their ideas to the whole class. That problem situation consisted partly of a report of a person who has a very special vision of insects and who keeps records of activities in a blog called "Diário do desestresse" [“De-stressing Diary”]. A printed version was given to each student to read attentively.

\section{Second Stage: Insects and Their Ecological Relationships}

Each group was supposed to present its ideas to the whole class after the realization of the previous activity. To help in the systematization of the facts we approached the ecological relationships between insects and other living creatures stressing aspects such as pollination and biological control, besides proposing a reflection on the processes of change in the natural 
space favoring the insertion of insects into the urban environment. The group participating in the activity was made up of fifteen students since they had been together for a year and already had a considerable level of affinity. There was a moment of dialogue in which each one had the opportunity to manifest his opinion in view of the statements of each group. All the activities of this meeting were recorded in audio, but there was a difficulty to transcribe them because on the date of the realization of this meeting various student activities and manifestations in the institution made it difficult to distinguish the sounds of the audio file.

Finally, at the third meeting we aimed at showing morphological and physiological aspects of insects by means of activities that favored the comparison between the initial student representations and the present scientific knowledge of insects.

\section{The Choice of the Video}

After the definition of the subject of the study and of the class in which it would take place, we looked for an educational documentary that would present ample possibilities for the exploration of the subject. The documentary tries to maintain a very close relationship with reality, respecting a determined set of conventions: recording in loco, no direction of the actors, use of natural settings, file images and others. For Melo (2002), the set of conventions above mentioned represents characteristic resources of a documentary, guaranteeing authenticity of what is represented, not being exclusive or indispensable to it. It demands an intervention, an authorial stance of the documentarian with regard to the sequence of images and sounds. "The documentary is not a film void of any implication. It always takes a position as a genre in which the essential thing is to stimulate a reflection on the world.” (Penafria, 1999: p. 76). To that end the theme approached must be seen from a determined point of view which will be reflected in the way the documentarian presents the facts.

"The effect of final meaning, therefore, is the result not simply of what is said, but essentially of how the theme is presented. It is precisely in that relationship between content and form that we find the authorial character of the documentary, a trait that we choose as a fundamental characteristic of the genre.” (Melo, 2002: p. 37).

We believe that a documentary requires that the succession and/or a superposition of images and sounds present not only the point of view adopted by the documentarian, but also that it be attractive. In the face of some possibilities we selected the DVD “Os insetos e o homem” produced by "Grupo de Imagem Científica" (GIC/IMAGO). These videos are available at the site: http://imago.ufrj.br/videos/index.html. They can be edited, copied and redistributed, provided that the source and authorship be cited.

\section{Analysis and Discussion of the Facts}

We stress the fact that we are merely presenting the analysis of the results obtained during the second meeting in which the documentaries were used.

The initial activities of the teaching sequence produced information which will orient the choice of the documentaries. The documentaries chosen were "Mosqutário-Estudando o Mosquito" [Mosquito Facility-Studying the Mosquito"] and "Parides ascanius: o resgate de uma espécie" [Parides ascanius: the rescue of a species”]. These documentaries are part of the
DVD collection “Os insetos e o homem”. The first documentary shows the opinion of two lay persons regarding the mosquito and then presents the development of the mosquito Aedes aegipty from the egg stage to the adult phase, besides showing the particularities of each morphological alteration. These mosquetoes are raised in the Mosquito Facility of the Medical Biochemistry Laboratory of UFRJ with the objective of furnishing material for research seeking to understand the aspects of the biology and biochemistry of this insect in order to produce tools for its control and blockage of the transmission of human illnesses, a fact that is stressed at the end of the documentary. The second documentary presents morphological, behavioral and reproductive aspects of the butterfly Parides ascanius popularly known as the beach butterfly. It shows various specific aspects of its development from the egg stage to its adult phase. It also stresses the ecological relationships established with other species, the harm caused by irregular occupation of protected areas, the fact that it is the first insect considered endangered of extinction in Brazil and the work of the researcher Dr. Luiz S. Otero who for more than 35 years has dedicated himself to the study of that species.

The first documentary was shown without interruption and then the second was shown with planned pauses, raising questions that had been previously elaborated in order to stimulate dialogue and discussion of ideas regarding the theme. Many students said that they had already observed the larva of the dengue mosquito in pools, in still water, in disposable cups, pots, tires, and cans. Another point stressed was the fact that the adult female of the mosquito feeds on blood while the larva feeds on matter available in the water. At certain moments we could observe the expressions of admiration before the images of the phase passage from pupa to adult individual. We observed that the students managed to establish distinctions between the habitat of the mosquito in the larva phase and in the adult phase, but in their answers they did not show that they had established relationships between morphological and physiological relationships and the metamorphosis or with the change of the feeding habits of the mosquito.

The second documentary approached the development of the butterfly in detailed form and stimulated the curiosity of the students. Regarding the process of development of a butterfly, Student 9 affirmed, "I never thought about that, only seeing the cocoon and knowing that from it would emerge the caterpillar that would become a butterfly”. That affirmation lead us to think that students vaguely recognize the phases of development of an insect which goes through a complete metamorphosis, but that they still have distortions in elaborating the process, since the caterpillar phase precedes the phase known as the pupa or cocoon phase, but yet the student affirms that there is a direct passage from the caterpillar to the butterfly phase.

It is worth noting the account of Student 11 who relates the theme of the documentary with her school experience during infancy: "I have already had an experience with this animal and how it reproduces itself, the cocoon, the larvae and when they become butterflies, what they eat and their metamorphosis and their butterfly species.” After attending the documentary she approaches other reproductive aspects and organizes more elaborate explanations relating the coloration of the insect to a defense strategy using coloration as an alert in the caterpillar and camouflage pigmentation in the chrysalis or pupa stage. Student 11 affirms with regard to the butterfly: "When she has copulated she does not receive any other male, the caterpillar 
[stage] is to defend itself and the chrysalis [stage] is a way of 'disguising' with the color of the substratum.” At this moment the teacher's systematic presentation had not yet taken place; the dialogue had occurred from the context presented in the documentary, which makes us raise the hypothesis that the use of the word "substratum" was associated to the presentation of the documentary and that at that moment the educational documentary aided the elaboration of more complex representations which leads us to believe that the documentary acted in this process as an important auxiliary learning resource.

Another relevant point is the attention given by the students to the process of metamorphosis; Student 7, upon being asked if he had ever seen butterflies reproducing, affirms: "I have already seen the cocoon"! And then in a second questioning about what else caught his attention he affirms: "the way that the chrysalis remains stuck. The caterpillar has several colors on account of the poison of the plants on which it feeds". The relationship established between nourishment and pigmentation in the caterpillar was also valued by several other students who in their answers also pointed out terms such as "toxins" and camouflage” which had not been previously cited. The student responses also stressed surprise at the duration of the caterpillar and chrysalis stages which in the species analyzed in the video, under favorable conditions, last thirty and twenty days, respectively; the students admitted that they had imagined quite shorter processes.

Images are of fundamental importance in the representation and communication of scientific knowledge. Employed as tools they make possible simultaneous visualizations of processes to be related, besides favoring the observation of what would hardly be visualized in everyday situations. Images are essential for science and the serve an important role in the visualization of what one wishes to explain (Silva et al., 2006: p. 220) and constitute an aid for the learning of scientific concepts since they can be more easily understood than textual language. "Images also contribute to the construction of other concepts and social values, transmitting images of nature and science and of scientific activities; building up authoritative knowledge and scientific discourse, helping to construct and change subjectivities.” (Vidal \& Rezende, 2010: p. 50).

For those authors images help in the elaboration of scientific concepts besides social values. The documentaries showed favored the organization of the attributes of concepts regarding the process of metamorphosis of insects by showing the chronological and physiological sequence of this phenomenon. Our theoretical perspective helps us to understand that new information is constructed from the interactions that take place between existing knowledge in the cognitive structure of the student and the information of the documentary. Those initial activities furnished widely encompassing information which oriented the teaching interventions. We understand conceptual change not as the substitution of an incorrect or naïve theory by a correct one, but rather as an opening of the conceptual space through the widening of the horizons, creating the possibility of considering different perspectives and different points of view regarding insects.

\section{The Experience of Others-Analogies Based on a Problem Situation}

The educational documentaries were presented in first instance so that certain considerations regarding insects might be elaborated. In order to provoke further discussion we read a problem situation: the "Diário do desestresse" ["De-stressing Diary”]. The text emphasizes the fear and repulsion that the author experiences regarding flying insects. During the text the author narrates the abrupt sequences she executes to kill a beetle which was living in her room, and when she finally managed to kill it she claims she did it in legitimate self-defense.

In the first question raised from the text the students are asked to take a stance regarding the attitude of the authoress who claims legitimate self-defense and the student is asked if he ever acted similarly. The majority of the students participating in the activity does not agree with the attitude of the authoress and affirms that she adopted a very aggressive attitude. At the same time some students state that this attitude is instinctive and that many are afraid of insects. From these reflections we were able to find statements like that of Student 6: “... it was she (the authoress) who invaded its space, its territory by building her home there as I already said and I don't agree with her attitude. It is clear that at some time in life I have killed some insect. But down deep, I don't like it.” At this time the student starts to ponder his own attitudes and his rejection of the attitude of the authoress. The student admits having killed insects, but with the stimulus to reflection he begins to give new meanings to the presence of insects in the urban environment; he expresses environmental considerations closer to present scientific knowledge. Finally the same student affirms "We human beings are the ones who are invading their territory". Contributing to this position Student 4 affirms "it's that insects are only looking for food and trying to defend themselves". We also find the affirmation of Student 8: "She acted out of fear or for disgust; I wouldn't act like that because it doesn't do anything to me! I wouldn't say 'legitimate defense', but I too have killed insects. Today I don't do that anymore!”

Adults develop their interpretations of daily events throughout life and teaching should consider the experience and knowledge of the student in order to understand his representations of reality. Thus lived experience is the foundation of the learning of the adult, in other words, it interferes in the way the adult takes a stance in the face of new experience, selects and interprets data. We consider that the exposition of the content of the documentary and the dialogue stimulated regarding the problem situation were important for the incentive and elaboration of new understanding regarding reality.

Further on in her text the authoress warns all insects: "Stay in nature because that's your place”, but she opens up an exception for butterflies and ladybugs which are always welcome in her house. Regarding that passage of the text, some students again referred to environmental changes as the cause of the presence of insects in the urban environment. We found affirmations such as: "because of deforestation insects are going to look for nourishment or shelter in the cities", "people are the ones who invaded nature; before our house there were woods on the site".

Finally we asked about the feelings related to the death of an insect and we observed descriptions opposed to the previous opinions. Student 6 who affirms that we invaded the habitat of the insects and justifies their presence in his house also affirms: "I feel relief when I kill a roach because it is a very repulsive beast". We observe that these results corroborate the results obtained by Costa Neto (2004) upon analyzing the culturally constructed attitudes in relation to those animals and how the semantic domain "Insect" is perceived and organized by hu- 
mans. For that author the way the majority of societies perceives and expresses itself regarding their relationship to insects themselves as well as no non-insect animals, identifying them as "insects", shows the attitudes and sentiments of disdain, fear and aversion which humans generally show for invertebrates. "Meanwhile those animals are perceived and classified according to ambiguous feelings, ranging from a positive attitude (conservationist) to a negative attitude (destructive)." (Costa Neto, 2004: p. 67). Such ambiguous attitudes were also expressed by our students who associate remorse and relief at the death of an insect.

\section{Final Considerations}

In the teaching process, we had recourse to the audiovisual because we consider it as a helpful instrument for teaching and learning to the extent that it is understood as a stimulus of new points of view on a specific theme or matter. We stress the importance of the role of the teacher to orient the students in the interpretation of the films and images. It is essential that there be understanding regarding the meanings attributed to the facts or phenomena studied or investigated. In fact, what we do is construct hypotheses regarding the representations of others.

Documentaries stand out among other audiovisual resources because they have the capacity to Record situations and happenings very easily. What we see in documentaries could also be seen in ourselves. In the documentary, the interpretations of the senses are not fixed to the audiovisual texts, but depend on how these are seen in relation to other texts. This interface of meaning is what we call "intertextuality". Meanings emerge through the interaction of the interpreter with the text within the particularities and restrictions of the context. "Meanings are contingent in relation to all three-image, observer and context" (Werner, 2004: p. 4).

The analysis of some activities makes it possible to raise the hypothesis that one of the criteria used by the student for the classification of animals is related to the relation that these living beings establish with man. Another hypothesis of representation that we can construct is that the adult student shows insecurity or failings in relation to the attributes of the concept of animal, which indicates a need to establish the biological criteria used in the taxonomical organization of living beings more clearly. It is relevant to mention that no student that included in the animal group living beings belongs to another kingdom.

Through analysis of the activities related to the exhibition of the documentaries, we observe that the students manage to establish distinctions between the habits of the mosquito in the larva stage and the adult stage, but in their answer, they did not show that they established relationships between the morphological and physiological changes regarding the metamorphosis and relations with the change of the feeding habits of the mosquito. The educational documentaries aided the elaboration of more complex representations, which leads us to believe that they acted in this process as an important auxiliary learning resource.

The documentaries exhibited favored the organization of the attributes of concepts regarding the process of metamorphosis of insects showing the chronological and physiological sequence of this phenomenon. Our theoretical perspective helps us to understand that new information is constructed upon present structures of knowledge, that is, some of the facts of the documentary established an exchange with existing information in the cognitive structure of the student.

\section{REFERENCES}

Costa Neto, E. M. (2004). Insects that “offend”: Artropodoses vision of the residents of the Serra da Jibóia, Bahia, Brazil. Sitientibus Série Ciências Biológicas, 4, 59-68.

Costa Neto, E. M., \& Carvalho, P. D. (2000). Perception of insects by graduates of the State University of Feira de Santana, Bahia, Brazil. Acta Scientiarum, Maringá, 22, 423-428.

Freire, P. (2002). Pedagogy of autonomy. Knowledge required for educational practice (25th ed.). São Paulo, SP: Paz e Terra.

Henschke, J. A., \& Cooper, M. K. (2006). International research foundation for andragogy and the implications for the practice of education with adults. In Proceedings of the 2006 midwest research-topractice conference in adult, continuing, extension and community education (pp. 93-98). St. Louis: University of Missouri.

Lima, M. L. O., Lima, V. H. M., Albuquerque, M. F. A., Silva, P., Lira, J. A. M., \& Silva, R. A. (2010). Perception of animals as "insects” by the residents of the village of Nazareth, Cabo de Santo Agostinho, Pernambuco. X Jornada de Ensino, Pesquisa e Extensão, Jepex, 1822 October 2010, Recife: UFRPE.

Ludojoski, R. (1972). Andragogy and adult education. México: Editorial Guadalupe.

Melo, C. T. V. (2002). The documentary genre as audiovisual. Comunicação e Lnformação, 5, 25-40.

Penafria, M. (1999). The documentary film: History, identity, technology. Lisboa: Editora Cosmos.

Posner, G., Strike, K., Hewson P., \& Gertzog, W. (1982). Accommodation of a scientific conception: Toward a theory of conceptual change. Science Education, 66, 211-227. http://dx.doi.org/10.1002/sce.3730660207

Inês, R. P. R. (2009). Experiential learning and wisdom in the adult and older adult. Dissertation (Master of Science in Education), Portugal: University of Lisbon.

Rachal, J. R. (2002). Andragogy's detectives: A critique of the present and a proposal for the future. Adult Education Quarterly, 37, 210227. http://dx.doi.org/10.1177/0741713602052003004

Silva, H. C., Zimmermann, E., Carneiro, M. H. S., Gastal, M. L., \& Cassiano, W. S. (2006). Caution when using images in science education. Ciência e Educação, 12, 219-233.

Vogt, M. S. L. (2007). Andragogy principles in the context of the teaching-learning process in physical therapy. Thesis, Brasília: University of Brasilia.

Werner, W. (2004). What does this picture say? Reading about the intertextuality of visual images. International Journal Social Education, 19, 1-10.

Zabala, A. (1998). The educational practice: How to teach. Porto Alegre: Artmed. 